www.volsu.ru

DOI: http://doi.org/10.15688/nav.jvolsu.2017.2.3

UDC 902.2

LBC 63.4(2)

\title{
GROUND BURIALS IN THE TERRITORY OF THE VOLGA-DON INTERFLUVE IN THE EARLY MIDDLE AGES ${ }^{1}$
}

\author{
Yakov A. Kiyashko \\ Volgograd State University, Volgograd, Russian Federation
}

\begin{abstract}
The article is devoted to the burial monuments in the territory of the Volga-Don interfluve in the early Middle Ages. This region was under the political control of Khazar Khaganate from the middle of the $7^{\text {th }}$ century to the second half of the $10^{\text {th }}$ century and people, who lived there, had different social, religious and ethnic features. The discussion about the boundaries extension of the sites of Saltovo-Mayaki culture and, consequently, about Khazar Khaganate has been recently resumed among the scientists. This problem has a particular importance for the territory of the Volga-Don interfluves, as it was the private domain of the Khazar tsar according to the written sources.

The main aim of this article is review of burials, which are distinguished among other burial monuments by the lack of the ground mound above the buried. There are eleven known places where ground burials were found. As a result of analysis, it was possible to find out that each of the objects was presented by a small number of burials. Almost all burials are dated back to the $7^{\text {th }}-10^{\text {th }}$ centuries. At the same time, they have serious differences which make the ethnic explanation much more difficult. The analysis of the ground burial near the village of Verkhnyaya Buzinovka took a special place in this research. The main peculiarity of these burials is a special structure of a burial chamber. The review of ground burials will allow updating the task of the comprehensive study of early medieval sites in the territory of the Volga-Don interfluve.

Key words: archaeological excavations, burial monuments, ground burials, Saltovo-Mayaki culture, Khazar Khaganate, Volga-Don interfluve.
\end{abstract}

Citation. Kiyashko Ya.A., 2017. Ground Burials in the Territory of the Volga-Don Interfluve in the Early Middle Ages. The Lower Volga Archaeological Bulletin, vol. 16, no. 2, pp. 50-66. (in Russian).

УДК 902.2

ББК 63.4(2)

\section{ГРУНТОВЫЕ ЗАХОРОНЕНИЯ НА ТЕРРИТОРИИ ВОЛГО-ДОНСКОГО МЕЖДУРЕЧЬЯ В ЭПОХУ РАННЕГО СРЕДНЕВЕКОВЬЯ ${ }^{1}$}

\author{
Яков Алексеевич Кияшко \\ Волгоградский государственный университет, г. Волгоград, Российская Федерация
}

\begin{abstract}
Аннотация. Статья посвящена погребальным памятникам эпохи раннего Средневековья на территории Волго-Донского междуречья. Этот регион с середины VII в. по вторую половину X в. был включен в сферу политического влияния Хазарского каганата, где проживало разное в социальном, религиозном и этническом плане население. В последнее время среди исследователей возобновилась дискуссия относительно границ распространения памятников салтово-маяцкой культуры, а следовательно, и Хазарского каганата. Данная проблема имеет особое значение для Волго-Донского междуречья, так как эта территория входила в личные владения царя хазар, что подтверждается письменными источниками.

Основной целью работы является обзор захоронений, которые выделяются среди остальных погребальных памятников отсутствием земляной насыпи над погребенным. Всего на рассматриваемой территории известно около одиннадцати мест, где были обнаружены грунтовые погребения. В результате анализа удалось установить, что каждый из объектов представлен небольшим числом захоронений. Практически все погребения датируются в рамках VII-X веков. При этом между ними существуют довольно серьезные разли-
\end{abstract}


чия, которые значительно осложняют их этническую интерпретацию. Особое место в работе занимает анализ грунтового могильника, который располагался у села Верхняя Бузиновка. Главной особенностью этих погребений является подбойная конструкция могильных камер. Это довольно редкий признак для бескурганных захоронений салтово-маяцкой культуры, особенно для территории волго-донских степей. Обзор грунтовых погребений салтово-маяцкой культуры позволит в дальнейшем реализовать задачу по комплексному изучению раннесредневековых памятников на территории Волго-Донского междуречья.

Ключевые слова: археологические раскопки, погребальные памятники, грунтовые могильники, салтово-маяцкая культура, Хазарский каганат, Волго-Донское междуречье.

Цитирование. Кияшко Я. А., 2017. Грунтовые захоронения на территории Волго-Донского междуречья в эпоху раннего средневековья // Нижневолжский археологический вестник. Т. 16, № 2. С. 50-66.

В результате многолетних археологических исследований раннесредневековых памятников междуречья Волги и Дона изменились некоторые представления по вопросу юго-восточной границы распространения салтовомаяцкой культуры. Если раньше считалось, что открытие «памятников типа Соколовской Балки» способствует выделению «нижневолжского» локального варианта салтово-маяцкой культуры, где раннесредневековые погребения, окруженные ровиками, стали бы главным признаком [Плетнева, 1999, с. 12], то в связи с новыми данными было отмечено определенное типологическое разнообразие некоторых элементов погребального обряда [Иванов, 1999, с. 220, 226; Круглов, 2013, с. 7482]. При этом подавляющее число средневековых захоронений, выявленных на территории Заволжья и Волго-Донского междуречья, относятся к периоду поздних кочевников IXХІ веков [Круглов, 2001, с. 395-446].

В связи с этим среди историков стал заметен определенный скепсис в вопросе локализации центра Хазарского каганата. Довольно долгое время считалось, что столица и личные владения кагана должны располагаться в районе нижнего течения реки Волги [Артамонов, 1962, с. 390], но существуют и другие точки зрения. В качестве примера следует привести гипотезу, согласно которой ставку кагана или столицу государства нужно искать на территории Нижнего Дона [Афанасьев, 2016, с. 41-72].

В результате закономерно возникает вопрос о правомерности включения района Волго-Донского междуречья в зону распространения салтово-маяцкой культуры. При этом необходимо учитывать неоднородность археологических памятников как внутри салтово-маяцкой культуры, так и среди погре- бений, оставленных кочевым населением IXXI веков.

Таким образом, на данный момент существует необходимость в комплексном анализе раннесредневековых памятников, которые датируются в рамках VII-X веков. Это позволит определить место изучаемого региона в государственном устройстве Хазарского каганата.

В рамках статьи осветить всю сложность вопроса не представляется возможным. Поэтому основная цель работы заключается в обзоре небольшой группы захоронений, при создании которых не возводились специальные земляные надмогильные сооружения. Всего известно около 11 мест на территории ВолгоДонского междуречья, где в разное время были открыты подобные памятники (рис. 1).

Первые три могильника находились на территории нынешнего города Волгограда. Так, существует информация, что в 19131914 гг. на правом берегу Волги было открыто несколько захоронений с глиняными сосудами. В одном из погребений найдено 12 золотых и некоторое количество медных монет «восточного типа» [Ильина, Шишкин, 1929, c. 22]. В 1927 г. в процессе городского строительства обнаружены грунтовые захоронения, которые были исследованы археологом П.Н. Шишкиным. Ученый отметил, что в одном погребении находились глиняные сосуды, а второе - сопровождалось скелетом коня. Всего на этом месте обследовано четыре захоронения. Из описания керамического материала был сделан вывод о принадлежности данных погребений к салтово-маяцкой культуре [Ильина, Шишкин, 1929, с. 10].

Еще одно захоронение, открытое на территории города, можно датировать в рамках VIII-X веков. Благодаря находке красногли- 
Ya.A. Kiyashko. Ground Burials in the Territory of the Volga-Don Interfluve

няной гончарной фляги-баклаги это погребение было отнесено к салтово-маяцкой культуре. К сожалению, из-за того, что объект оказался разрушен в процессе строительства завода, дополнительная информация о нем отсутствует.

Один из немногочисленных грунтовых могильников был открыт во время работы археологической экспедиции под руководством Е.В. Круглова недалеко от с. Оленье Дубовского района Волгоградской области (рис. 2,1б). В обрыве береговой полосы Волгоградского водохранилища было исследовано три объекта, которые отличались разной степенью сохранности. Все захоронения располагались в прямоугольных ямах с закругленными углами. Погребенные лежали на спине, ориентированы на запад-северо-запад. В двух погребениях справа за головой находилась керамическая посуда и железные ножи. При этом в первом погребении найдены остатки скелета барана. В третьем - сохранились лишь разрозненные кости взрослого человека и два позвонка животного [Круглов, 1990, с. 57-59].

В 1990-1991 гг. археологической экспедицией Волгоградского государственного университета, под руководством А.Н. Дьяченко, проводились раскопки курганных могильников в Клетском районе Волгоградской области [Дьяченко, Кригер, 1991, с. 3]. Во время работ в 6 км к северо-западу от с. Верхняя Бузиновка, в обрезе берега реки Крепкая, был обнаружен грунтовый могильник, состоящий из трех погребений (рис. 3,1,2). В результате исследований памятник датирован в рамках IX-X вв. н.э. и отнесен к болгарскому варианту салтово-маяцкой культуры [Дьяченко, Кригер, 1991, с. 63]. Главной особенностью погребального обряда данных захоронений является подбойная конструкция могильной камеры, что для грунтовых погребений салтово-маяцкой культуры, особенно открытых на территории Волго-Донского междуречья, является редким признаком. Некоторые особенности вышеуказанного памятника частично упоминаются в научной литературе [Круглов, 2006 , с. 262], поэтому стоит остановиться на нем более подробно.

Общая площадь раскопа грунтового могильника за два года исследований составила $334 \mathrm{~m}^{2}$. Всего выявлено три объекта, которые отличались похожим погребальным обрядом. Погребение № 1 обнаружено местными жителями в обрезе берега. По сохранившейся конструкции захоронения был сделан вывод о наличии подбоя в северо-восточной стенке могилы. Могильная яма ориентирована длинными сторонами по линии ЮВ-СЗ. Длина 1,8 м, глубина - 1,8 м от материка. Скелет женщины (?) располагался на спине в вытянутом положении. Череп находился в северозападной части погребения. Среди инвентаря зафиксирован сероглиняный лощеный кувшин с канелюрами на тулове сосуда, а также стеклянные бусы в количестве 13 штук (рис. 4,34). Стоит отметить, что расположение инвентаря в могиле не известно, так как она была разрушена и вещи и большая часть скелета лежали вне могильной ямы. Фрагменты заупокойной пищи или костей сопровождающего животного не найдены.

Могильное пятно погребения № 2 было обнаружено северо-восточнее погребения № 1 и ориентировано по линии СЗ-ЮВ (рис. 3,1 ). Могила имела подбой в восточной стенке. На противоположной стороне ямы была зафиксирована ступенька шириной 0,2 м и высотой 0,1 м. Длина погребения составляет два метpa, ширина по дну камеры - 0,65-0,7 м; глубина $-0,65$ м. Скелет, ориентированный на С3, был вытянут на спине и принадлежал женщине 25-30 лет. Кисти рук находились под тазом, за черепом располагалась нога барана. Погребальный инвентарь отсутствовал.

Погребение № 3 локализовалось северозападнее погребения № 2 (рис. 3,2). Могильное пятно также было ориентировано по линии СЗ-ЮВ. Конструкция ямы аналогична погребению № 2. Ширина ступеньки 0,1 м, высота 0,2 м. Длина - 1,95 м, ширина - 0,52 м, глубина - 1,1 м по материку. Скелет так же как и в предыдущем захоронении принадлежал женщине монголоидного расового типа 18-20 лет. Он располагался на спине, головой на С3, руки вытянуты вдоль туловища. Среди могильного инвентаря присутствует сероглиняный лощеный кувшин, который располагался за черепом погребенной (рис. 3,6). Орнамент представлен в виде двух резных линий по основанию горловины. Кроме этого, найдено несколько небольших ножичков (рис. 3,4 ), которые былы интерпретированы как набор 
туалетных принадлежностей, железный предмет и железное кольцо с крючком и креплением к ремню (рис. $3,4,5$ ). Следы заупокойной пищи отсутствовали.

Таким образом, наиболее общими чертами данных захоронений являются подбойные сооружения, со ступенькой, северо-западная ориентировка погребенных, а также женская принадлежность скелетов. При этом прослежены определенные различия. Так, в погребении № 1 и 3 встречен довольно разнообразный инвентарь, а также сероглиняные лощеные кувшины. В погребении № 2 вещи отсутствовали, но в отличие от других захоронений, в нем была найдена нога барана. Вполне возможно, что данные различия обусловлены различным социальным статусом погребенных. В заключение стоит добавить, что погребение № 3 принадлежало женщине монголоидного расового типа, а в погребении № 2 был погребен монголоидно-европеоидный метис, где монголоидные черты преобладали [Балабанова, 2005, с. 65, табл. 1].

Следующий грунтовый могильник был обнаружен в береговом обрезе Цимлянского водохранилища у ст. Приморская Калачевского района Волгоградской области [Мамонтов, 1985] (рис. 5,1-3). Информации относительно могильника крайне мало. Сохранился чертеж двух погребений, где погребенные лежали вытянуто на спине, ориентированные головой на 3. Руки располагались вдоль тела. За головой находились керамические сосуды, характерные для салтово-маяцкой культуры (рис. 5,2,3). В одном захоронении, справа от скелета человека, находились остатки костей овцы. В другом - фрагменты железного ножа и подвески. Информация о размерах могильных ям или их конструкционных особенностях отсутствует.

Другой объект, который располагался на правом берегу Карповского водохранилища, в окрестностях поселка Ильевка, был случайно открыт во время работ археологической экспедиции под руководством В.И. Мамонтова [Мамонтов, 1988]. Особый интерес представляет погребение № 3, которое было сильно разрушено в процессе обрушения части берега (рис. 4,1).

Вдоль северо-восточной стенки могильной ямы проходила ступенька, на которой рас- полагался скелет барана и череп лошади. Погребенный мужчина монголоидного облика был ориентирован головой на северо-восток. Рядом с ним, на приступке, располагался лепной глиняный сосуд (рис. 4,2). Предварительно погребение датируется IX-XI вв. и относится к погребальным памятникам поздних кочевников.

Одно грунтовое погребение было найдено во время раскопок русского кладбища на территории золотоордынского города, в литературе известного как Водянское городище [Мыськов, 1989]. Могильная яма погребения № 6 имела овальную форму (рис. 5,4). Скелет лежал на левом боку, головой был ориентирован на северо-запад. Ноги согнуты в коленях, череп отсутствовал [Мыськов, 2001]. Наличие лепного сосуда (рис. 5,5) и пряслиц, изготовленных из стенок амфор, позволило отнести этот объект к памятникам салтово-маяцкой культуры [Круглов, 2006].

Еще одним раннесредневековым захоронением является погребение № 11 грунтового могильника у с. Хошеутово. Из опубликованной на сегодняшний день информации известно, что погребение было совершено в катакомбной могиле. Среди инвентаря присутствует лук «огуро-савирского» типа, а также четыре пряжки, что позволило Е.В. Круглову датировать погребение концом V - 1-й половиной VI века [Круглов, 2006, с. 264].

Определенный интерес представляет захоронение, которое было обнаружено на левом берегу Сердитой балки, недалеко от с. Перекопка Клетского района Волгоградской области [Лапшин, 2008, с. 318-319]. Погребение из-за оползня было разрушено, поэтому большая часть могильного инвентаря собрана на дне склона балки (рис. 6,1). В процессе предпринятого осмотра выяснено, что погребенный мужчина лежал вытянуто на спине и был ориентирован головой на запад с небольшим отклонением к югу. Сохранившаяся правая рука располагалась вытянуто вдоль туловища, кисть покоилась на тазе погребенного. Череп скелета повернут направо. На правой стороне, рядом с черепом, был найден палец лошади и лопатка и позвонки барана. Среди могильного инвентаря присутствовали детали поясного набора, состоящего из серебряных блях и заклепок различной формы 
(рис. 6,2). Бронзовая цельнолитая пряжка находилась у правой плечевой кости погребенного. Кроме этого, были найдены наконечники черешковых стрел листовидной формы, кремневый отщеп и фрагмент ножа. Последующие изыскания на мысовой площадке новых погребений не выявили.

В контексте сказанного стоит отметить еще одно грунтовое захоронение у с. Успенка в Астраханской области [Шнайдштейн, 1989, c. 269-272]. Это погребение было расположено на первой надпойменной террасе левого берега р. Ахтуба, на склоне оврага (рис. 6,3). Скелет взрослой женщины располагался в простой прямоугольной яме, вытянуто на спине, головой на 3. Южная сторона могильной конструкции разрушена траншеей водоочистных сооружений, в которой были найдены кости черепа и ног лошади. Следовательно, не представляется возможным отметить расположение чучела коня в погребальной яме, однако, если опираться на чертеж захоронения, то можно предположить, что шкура располагалась на дне могильной ямы, справа от скелета. Кроме этого, в процессе исследования погребенной было установлено ритуальное связывание ремнем ног и разрушение скелета. Фрагменты заупокойной пищи отсутствовали.

В результате обзора памятников раннесредневекового времени следует акцентировать внимание на их крайнюю малочисленность. Как уже отмечалось, всего известно около одиннадцати мест, где были открыты данные захоронения. При этом стоит сказать, что из них только памятники, найденные в довоенном городе Волгограде, а также недалеко от населенных пунктов Оленье, Верхняя Бузиновка, Приморская, могут быть названы могильниками. Несмотря на это, общее количество погребений крайне малочисленно (от 2 до 4). Все остальные объекты представляют собой одиночные захоронения.

Небольшое количество известных погребальных памятников этого времени обусловлено, скорее всего, не слабой распространенностью грунтовых могильников, а сложностью их обнаружения. Открытие данных объектов чаще всего происходит случайно, например, в процессе современного строительства или обвала береговой линии водохранилищ. Интерес вызывает небольшое количество погребений в рассматриваемых могильниках, а также наличие одиночных захоронений. К тому же следует учесть широкую разновидность погребального обряда среди данных памятников.

Как известно, среди грунтовых погребений салтово-маяцкой культуры выделялось два обряда захоронения, связанных с трупоположением [Плетнева, 1967, с. 71-100]. Первый, совершенный в катакомбных могилах, соотносился с аланским населением (Салтово), второй, в простых грунтовых ямах, с болгарским (Зливки). В дальнейшем был сделан вывод о том, что катакомбные погребения являются преобладающим признаком на памятниках лесостепной зоны распространения салтово-маяцкой культуры. Для степной же зоны характерны захоронения зливкинского типа. При этом погребения в подбоях как отдельный тип не рассматриваются и обычно приводятся в контексте с простыми ямными погребениями [Плетнева, 1967, с. 94-95].

Среди рассматриваемых нами объектов зафиксировано только одно захоронение, где погребенный был помещен в катакомбу. Это погребение у с. Хошеутово, которое датируется концом V - 1-й половиной VI в., то есть позднегуннским или раннетюркским периодом.

Памятники на территории современного г. Волгограда (за исключением захоронения с наличием костных остатков лошади), у ст. Приморской и у с. Оленье, выделяются сооружением простых погребальных ям с помещением скелета вытянуто на спине, головой, ориентированной на запад с сезонными отклонениями на север. Присутствие керамической посуды салтово-маяцкой культуры указывает на известные ямные захоронения зливкинского типа. Такие погребения, по мнению большинства исследователей, относятся к болгарскому населению салтово-маяцкой культуры и датируются в рамках VIIIIX веков [Ляпушкин, 1958, с. 146-147; Плетнева, 1967, с. 92-94; Круглов, 1990, с. 57-59].

Три погребения из грунтового могильника Верхняя Бузиновка отличаются от остальных объектов прежде всего сооружением подбойной камеры в восточной или северо-восточной стенке могильной ямы, с сооружением ступеньки с противоположной стороны. Судя по вещественному материалу, все три погребения можно отнести к IX веку. 
Как уже было отмечено выше, подбойные могильные сооружения часто учитывались вместе с простыми ямными могилами, и относились к грунтовым памятникам зливкинского типа степной зоны салтово-маяцкой культуры. Несмотря на это, стоит отметить, что на большинстве известных и изученных могильниках лесостепной зоны встречаются погребения, совершенные в грунтовых простых и подбойных ямах [Плетнева, 1999, с. 13, табл. 1]. К этому стоит добавить и информацию о последних исследованиях погребений Зливкинского могильника, где было подмечено широкое разнообразие погребального обряда [Швецов, 1983, с. 341].

Среди исследователей нет единого мнения относительно этнической атрибуции подбойных захоронений. Так, С.А. Плетневой была выдвинута версия о болгарской принадлежности ямных погребений Дмитриевского археологического комплекса [Плетнева, 1989, с. 255-259]. Подбойные же конструкции (а всего их было найдено три) также связывались с болгарами. При этом исследовательница предполагала возможность их аланской принадлежности [Плетнева, 1989, с. 259]. Женские ямные захоронения, открытые на территории Маяцкого могильника, были охарактеризованы как болгарские. Детские ямные погребения, по мнению В.С. Флерова, возможно, принадлежали представителям смешанных браков между аланами и болгарами. Интерес представляет тот факт, что среди погребений встречены и подбойные захоронения как мужчин, так и женщин [Флеров, 1993, с. 34-42].

Версию о том, что ямные грунтовые захоронения на могильниках лесостепной зоны оставлены болгарским населением раскритиковал Г.Е. Афанасьев. Исследователь обратил внимание на отсутствие достаточной аргументации, а также указал, что данные памятники могли быть оставлены представителями разных этнических групп [Афанасьев, 1987, c. 147-150].

Аналогичные верхнебузиновским комплексам, известны захоронения в грунтовых могилах Верхне-Салтовского могильника, где погребения подростков в ямах с подбоем рассматриваются в качестве аланского компонента салтово-маяцкой культуры [Хоружая, 2013, c. 211-224]. Изменения конструкции могиль- ной ямы (от катакомбы в сторону подбоя), вероятно, могут быть связаны с преждевременной смертью индивидов, вследствие возможной болезни [Хоружая, 2013, с. 220]. Этим следует объяснить и небольшое количество захоронений в могильнике (всего 3), которые, видимо, соорудили вдали от всего остального массива [Хоружая, 2013, с. 220].

В контексте данной версии можно было бы и рассматривать погребения у хут. Верхняя Бузиновка, так как могильник также состоял всего лишь из трех захоронений, а дальнейшие раскопки новых объектов не выявили. Однако в процессе изучения палеопатологических особенностей черепов скелетов из погребений № 2 и № 3 следов каких-либо инфекций не было выявлено [Перерва, 2003, c. 180-185].

В результате можно выделить три основные точки зрения на интерпретацию грунтовых могил с подбоями на территории лесостепной зоны распространения салтово-маяцкой культуры. Первая отражает возможную связь погребений с единичными представителями болгарского населения, которое проживало среди донских алан. Вторая точка зрения указывает на аланскую принадлежность памятников, при этом отмечается изменение погребального обряда в связи с демографическими признаками погребенного (возраст, преждевременная смерть и т. д.). Последняя точка зрения связывает изменение конструкции погребальной камеры со смешением аланского и булгарского населения.

Закономерно возникает вопрос о месте верхнебузиновских погребений в структуре памятников салтово-маяцкой культуры ВолгоДонского междуречья. Так, существует гипотеза Е.В. Круглова, что данные захоронения следует отнести к поздним памятникам соколовского типа [Круглов, 2006, с. 262]. Возможное существование бескурганных захоронений соколовского типа было продемонстрировано исследователем на примере грунтового погребения у пос. Ильевка [Круглов, 2004, с. 180186]. В качестве аргументации выделены следующие характерные черты этого объекта: расположение погребения на территории уже существовавшего курганного могильника, индивидуальный характер захоронения, положение погребенного мужчины вытянуто на спине, 
сооружение погребальной камеры в южной части могильной ямы, а ступеньки в северной, сопровождение погребенного частичными останками сразу двух ритуальных животных, коня и барана, наличие глиняного лепного сосуда [Круглов, 2004, с. 182].

Вышеперечисленные признаки сближают это захоронение с подкурганными погребениями «типа Соколовской Балки» (VIIIIX вв.), за исключением трех компонентов это отсутствие курганной насыпи, подкурганной ритуальной площадки, окруженной ровиками, а также погребальной камеры с подбоем. При этом северо-восточная ориентировка не характерна для вышеупомянутого типа памятников. Если первые два признака и ориентировка погребенного имеют определенную вариативность, то подбойная конструкция являлась наиболее жестким признаком. Однако могила была разрушена в юго-западной части, что не позволяет точно проследить конструкцию погребальной камеры. Отсутствие ритуальной площадки и насыпи, по мнению Е.В. Круглова, можно объяснить более низким социальным статусом погребенного [Круглов, 2004, с. 183-184].

Предположение о существовании поздней группы бескурганных памятников «типа Соколовской Балки» подразумевает наличие общих признаков между верхнебузиновскими комплексами и грунтовым погребением у пос. Ильевка. Но при их сопоставлении сразу можно отметить некоторые существенные различия. Так, подбойная конструкция в женских погребениях сооружена в восточной длинной стенке могильной ямы, а не в южной. При этом отсутствуют кости сопровождающего животного (лошади) и т. д. Вполне возможно, что за этими признаками действительно следует видеть изменение погребального обряда под давлением социального или экономического фактора. Но прежде чем попытаться выделить данный аспект, необходимо обратить внимание на общую черту этих памятников отсутствие курганной насыпи.

Относительно данной проблемы, среди исследователей довольно широкое распространение получила точка зрения Г.А. Федорова-Давыдова о том, что грунтовые захоронения оставлены населением, хозяйственно-экономический уклад которого определяется оседлым образом жизни [Федоров-Давыдов, 1966, с. 131]. В качестве примера можно привести грунтовое погребение № 6 раскопа II на территории золотоордынского кладбища Водянского городища. Несмотря на то что подавляющее большинство объектов датируются XIV в., особенности погребального обряда погребения № 6, а также могильный инвентарь позволяет его рассматривать в рамках второй половины VIII - начала IX века. Подобные захоронения довольно часто встречаются среди памятников салтово-маяцкой культуры [Плетнева, 1967, с. 94-98; Плетнева, 1989, с. 255-259; Михеев, 1985, с. 18].

Помимо этого, существуют грунтовые захоронения, сопровождающиеся остатками коня и характерным инвентарем кочевнических племен. Одним из таких памятников является одиночное погребение, открытое на краю Сердитой Балки, которое выделяется присутствием поясного гарнитура и костей мелкого рогатого скота и лошади. Автором раскопок погребение было отнесено к древностям огузо-печенежского круга и датировалось в хронологических рамках X-XI веков [Лапшин, 2008, с. 318]. Другим - грунтовое погребение у с. Успенка. Первоначально, в процессе исследования захоронения, Е.В. Шнайдштейн датировала его в рамках Х в. и связала с населением Хазарского каганата [Шнайдштейн, 1989, с. 269-272]. В дальнейшем была предложена точка зрения об огузской интерпретации этого захоронения, с учетом совпадения погребального обряда с другими памятниками поздних кочевников в регионе [Круглов, 2001 , с. 413]. Однако стоит отметить, что оба объекта серьезно пострадали в силу различных природных или хозяйственно-строительных причин. Это, в свою очередь, вносит некоторую условность при определении этнической принадлежности захоронений. При этом остается открытым вопрос насчет формирования кочевнических грунтовых погребений. Вполне возможно, что отсутствие земляной насыпи продиктовано желанием сокрыть место захоронения. Эта традиция хорошо известна у монгольских кочевых племен [Путешествия..., 1957, с. 32-33, 102], но связывать ее с вышеупомянутыми памятниками, с учетом их крайней малочисленности, на данный момент преждевременно. 
Я.А. Кияшко. Грунтовые захоронения на территории Волго-Донского междуречья

В результате анализа грунтовых погребений на территории Волго-Донского междуречья следует выделить некоторые моменты. Вопервых, это небольшое количество известных на сегодняшний день могильников в регионе. При этом они содержат крайне малое число захоронений. Во-вторых, практически все погребения датируются в рамках второй половины VIII - X в., за исключением погребения у пос. Ильевка, которое, может, относится и к первой половине VIII века. В-третьих, это наличие существенных различий в погребальном обряде рассматриваемых захоронений, что значительно осложняет их этническую интерпретацию. Так, на данный момент нельзя с полной уверенностью определить место подбойных грунтовых захоронений, найденных у с. Верхняя Бузиновка, в структуре погребальных памятников салтово-маяцкой культуры.

Несмотря на это, необходимо все же отметить возможную взаимосвязь между подкурганными и грунтовыми захоронениями, что, в свою очередь, указывает на необходимость в проведении анализа курганных комплексов VII-X вв. с перспективой выделения наиболее характерных признаков погребального обряда и сопоставления их с различными группами населения, проживавшего на территории Волго-Донского междуречья в раннем Средневековье. 


\section{ИЛЛЮСТРАЦИИ}

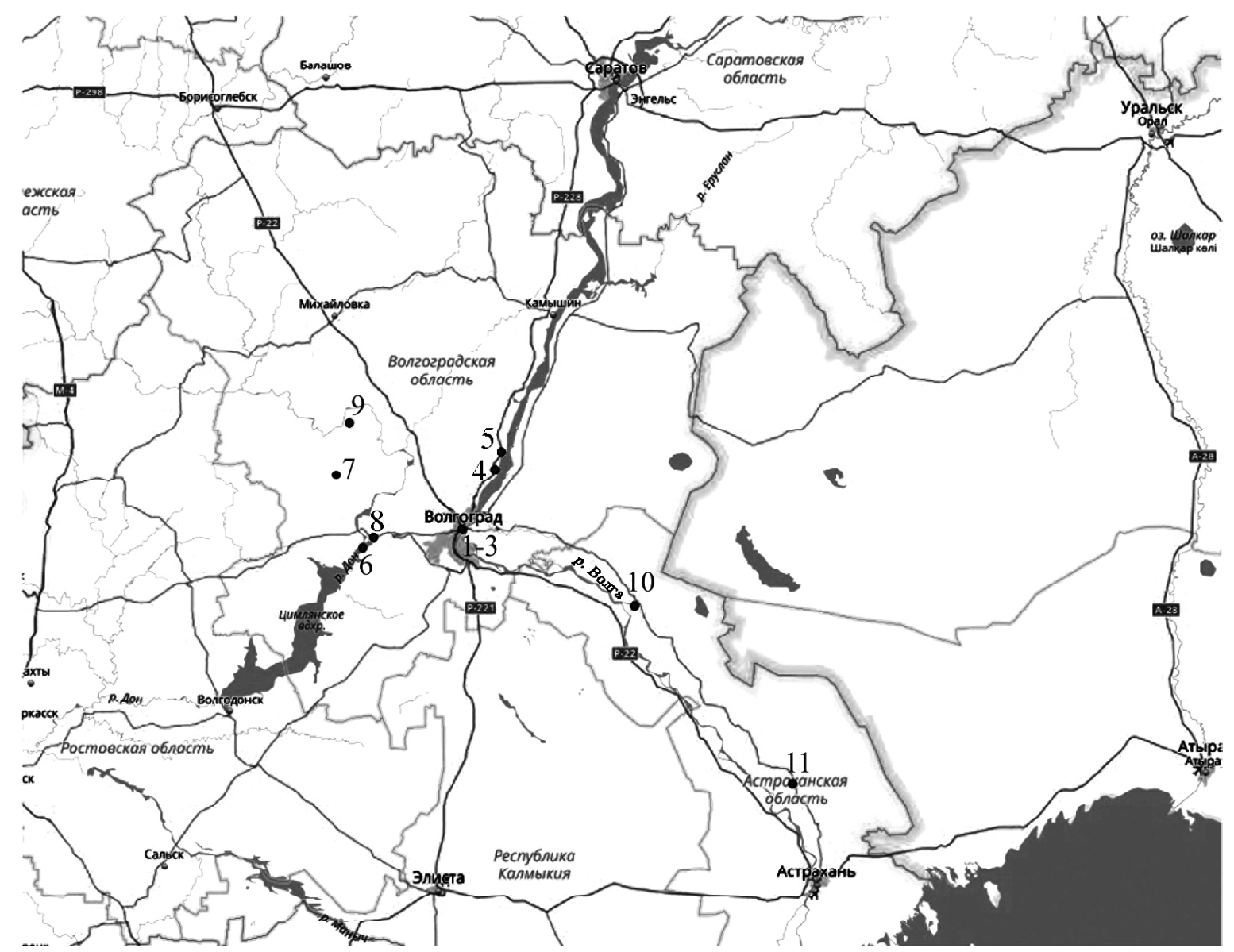

Рис. 1. Карта месторасположения грунтовых захоронений эпохи раннего Средневековья на территории Волго-Донского междуречья:

1-3 - грунтовые могильники на территории г. Волгограда; 4 - Водянское городище; 5 - Оленье; 6 - Приморский; 7 - Сердитая Балка; 8 - Ильевка; 9 - Верхняя Бузиновка; 10 - Хошеутово; 11 - Успенка

Fig. 1. The map of the ground burials' location of the Early Middle Ages in the territory of the Volga-Don interfluve:

$1-3$ - the ground burials in the territory of Volgograd city; 4 - Vodyansky hillfort; 5 - Olenye; 6 - Primorsky; 7 - Serditaya Balka; 8 - Ilyevka; 9 - Verkhnyaya Buzinovka; 10 - Khosheutovo; 11 - Uspenka 


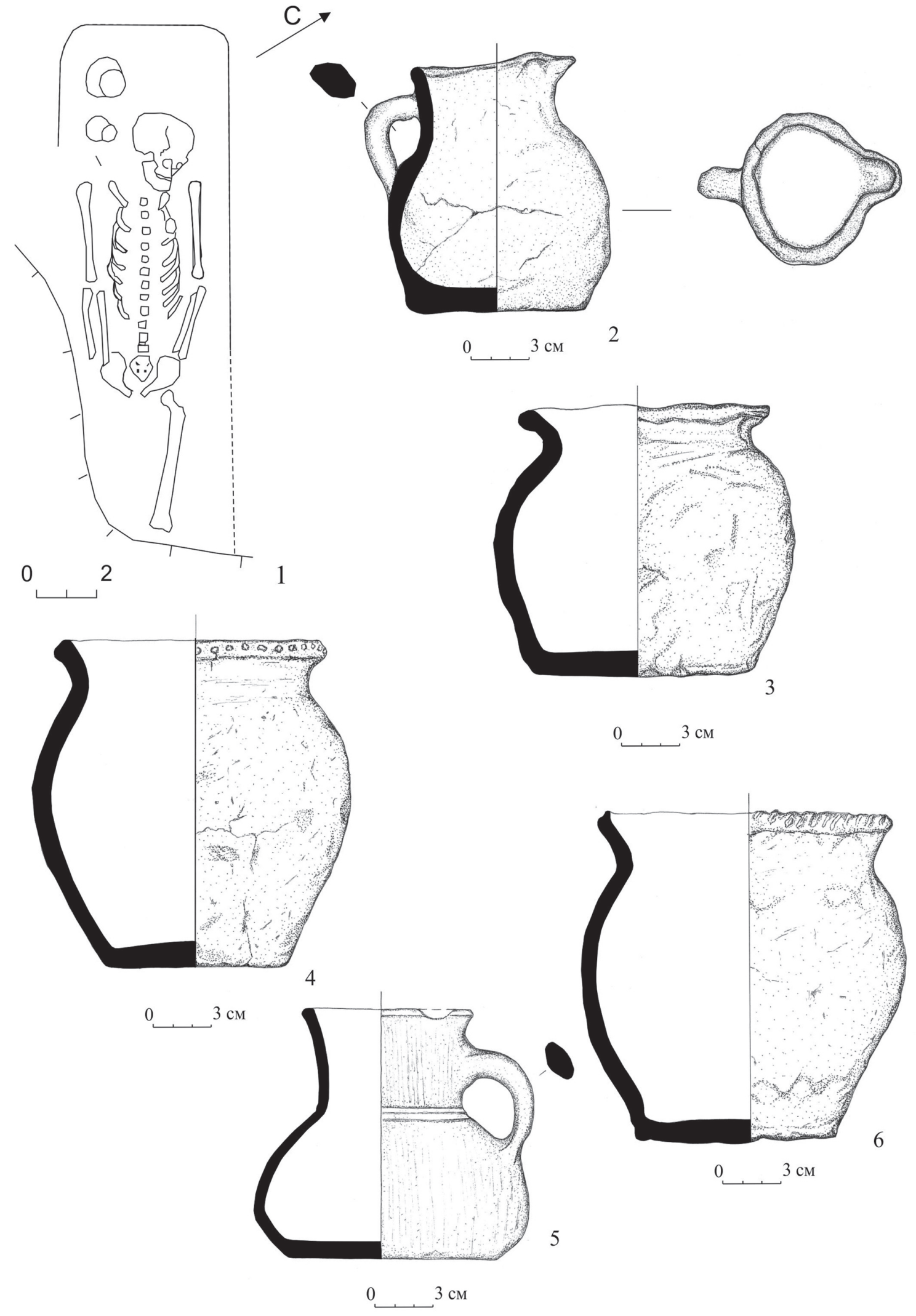

Рис. 2. Материалы грунтового могильника Оленье:

1 - план погребения № 2 [Круглов, 1990, с. 58, рис. 1]; 2, 3 - погребение № 2; 4, 5 - погребение № 1; 6 - погребение № 3

Fig. 2. The materials from Olenye ground burial:

1 - plan of burial 2;2,3- burial 2;4,5- burial 1;6-burial 3 
Ya.A. Kiyashko. Ground Burials in the Territory of the Volga-Don Interfluve

\section{Погребение № 2}
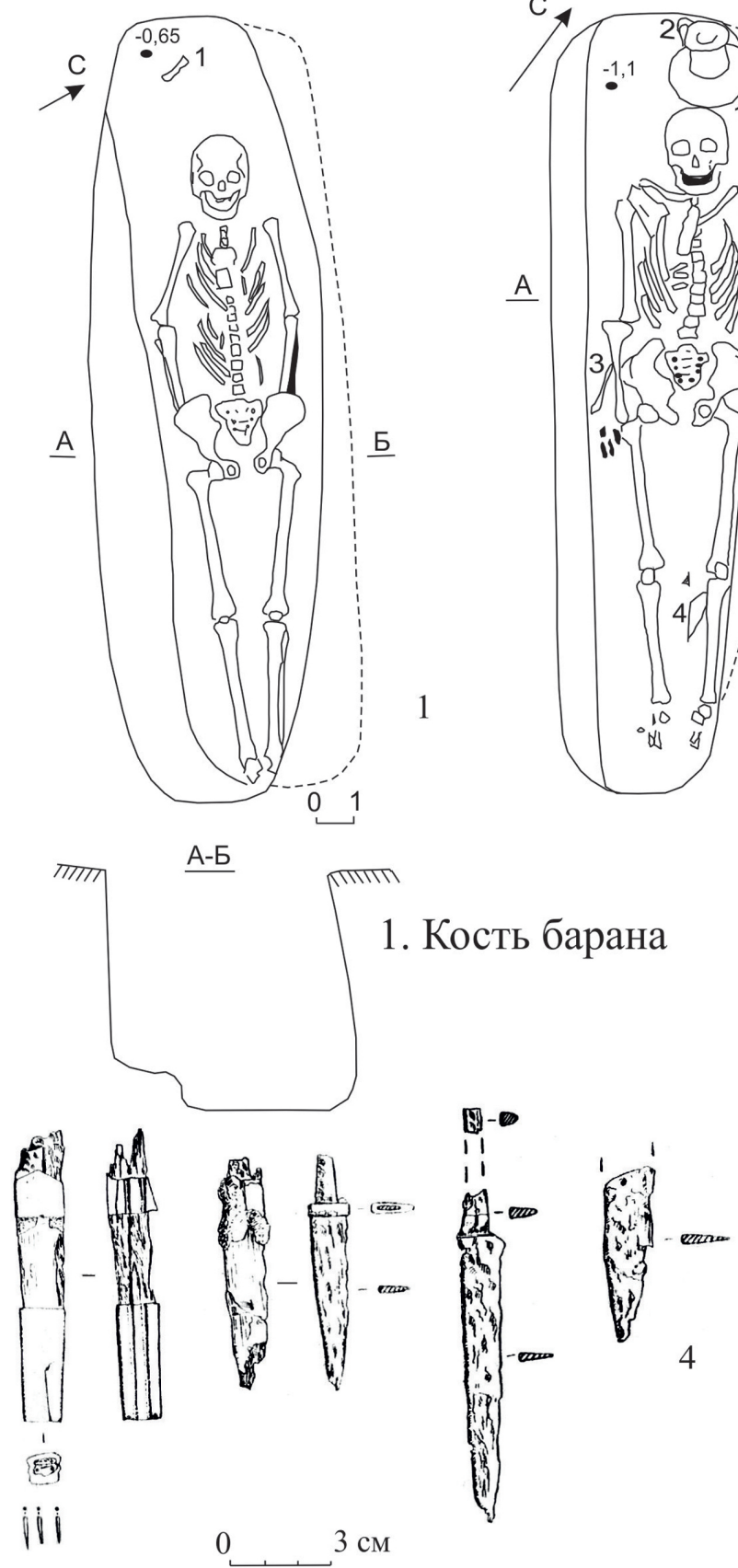

$\underline{A}$
Погребение № 3
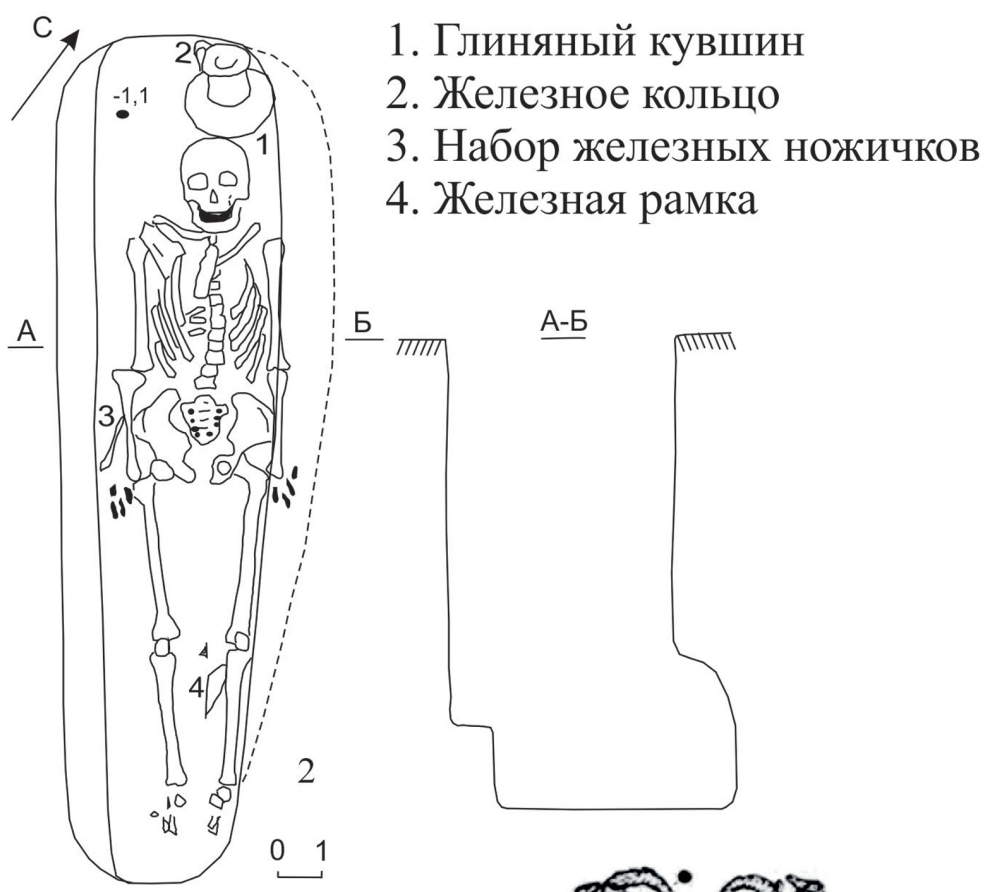

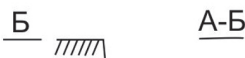
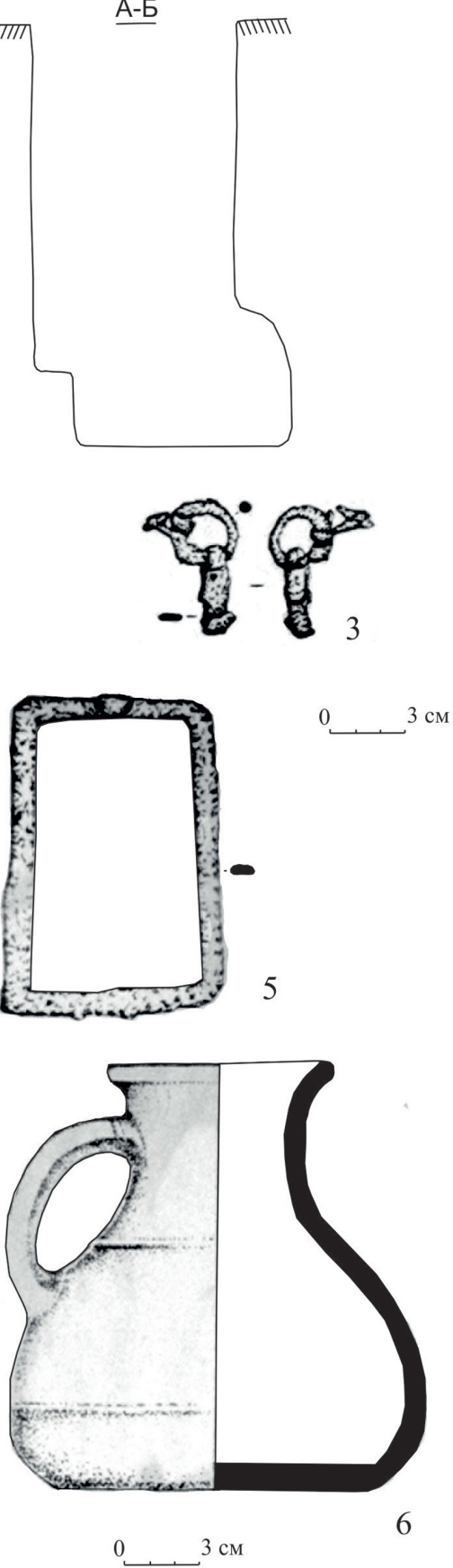

Рис. 3. Грунтовый могильник Верхняя Бузиновка:

1 - план погребения № 2; 2 - план погребения № 3; 3-6 - могильный инвентарь из погребения № 3 Fig. 3. The materials from the ground burial of Verkhnyaya Buzinovka:

1 - plan of burial 2;2 - plan of burial 3;3-6- materials of burial 3 
Я.А. Кияшко. Грунтовые захоронения на территории Волго-Донского междуречья
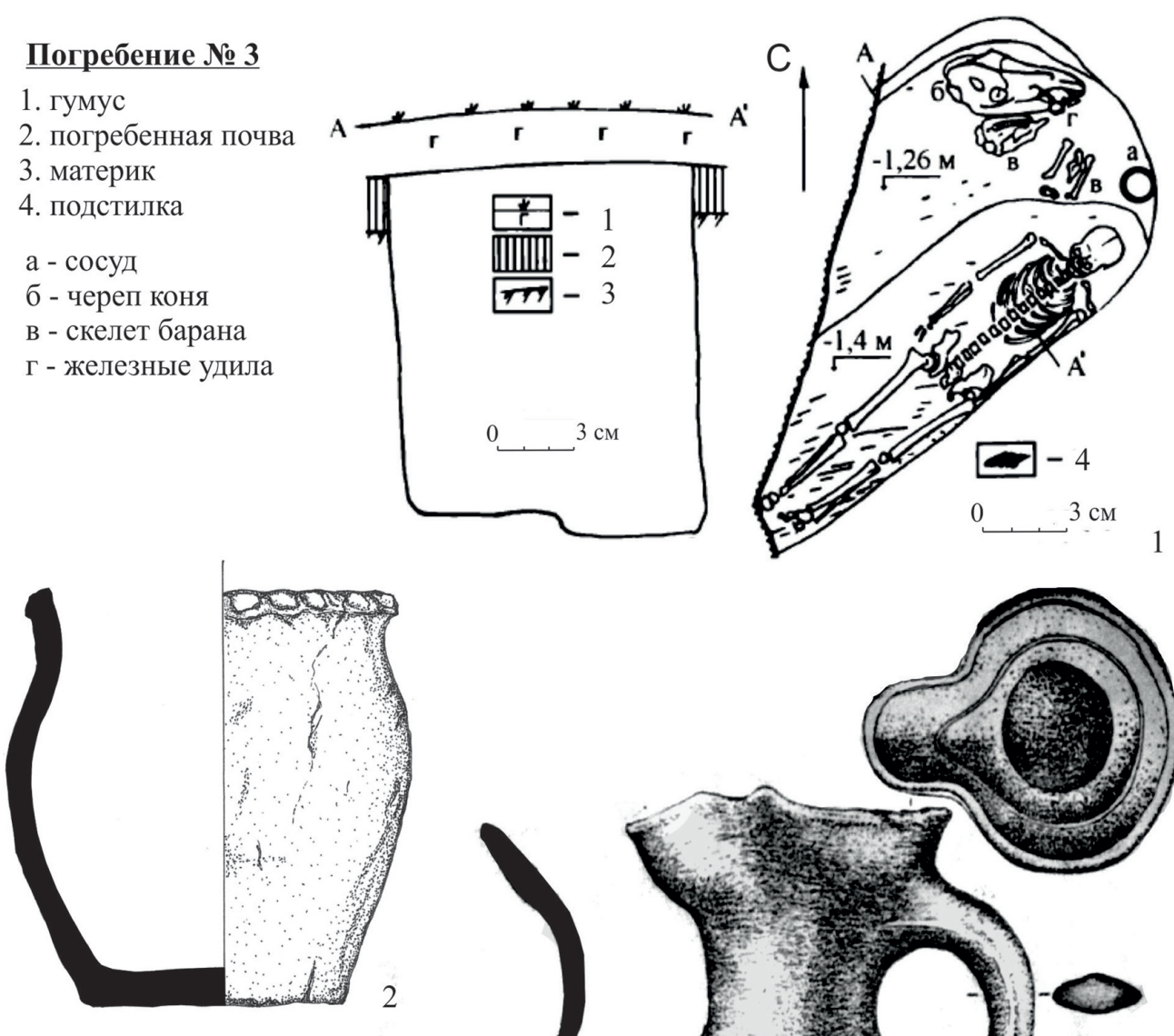

0 $3 \mathrm{~cm}$
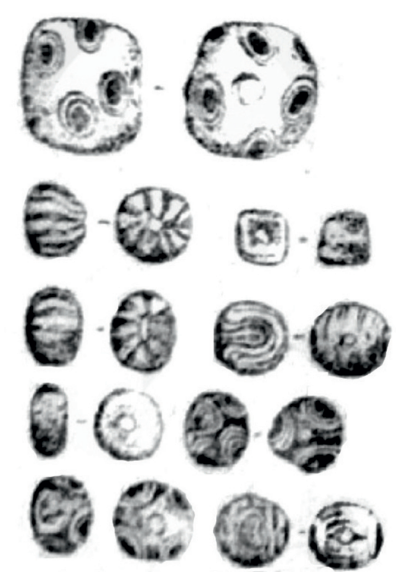

603

0 $3 \mathrm{~cm}$
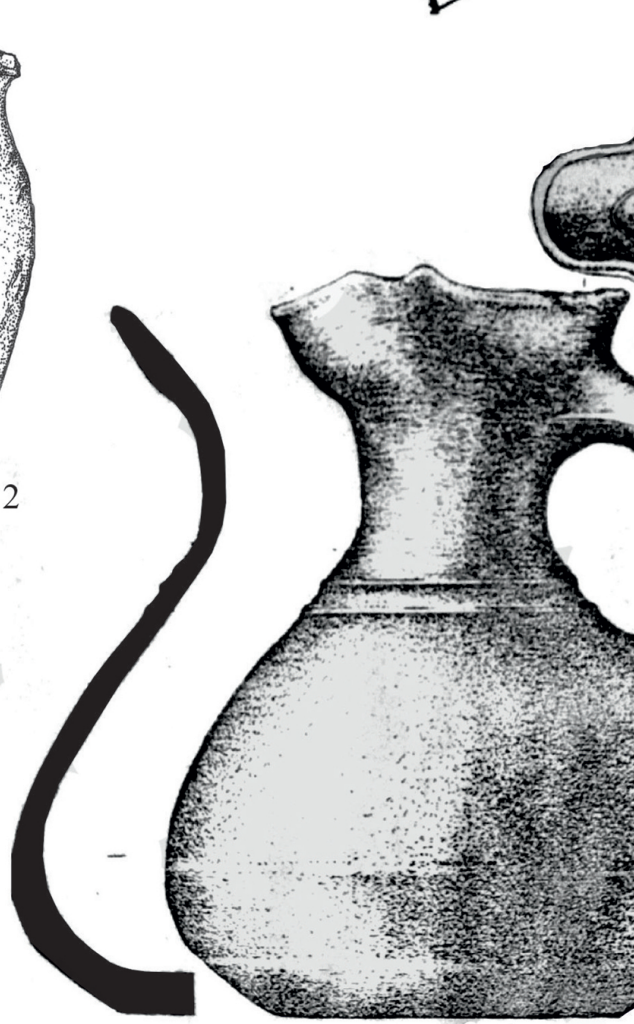
Ya.A. Kiyashko. Ground Burials in the Territory of the Volga-Don Interfluve
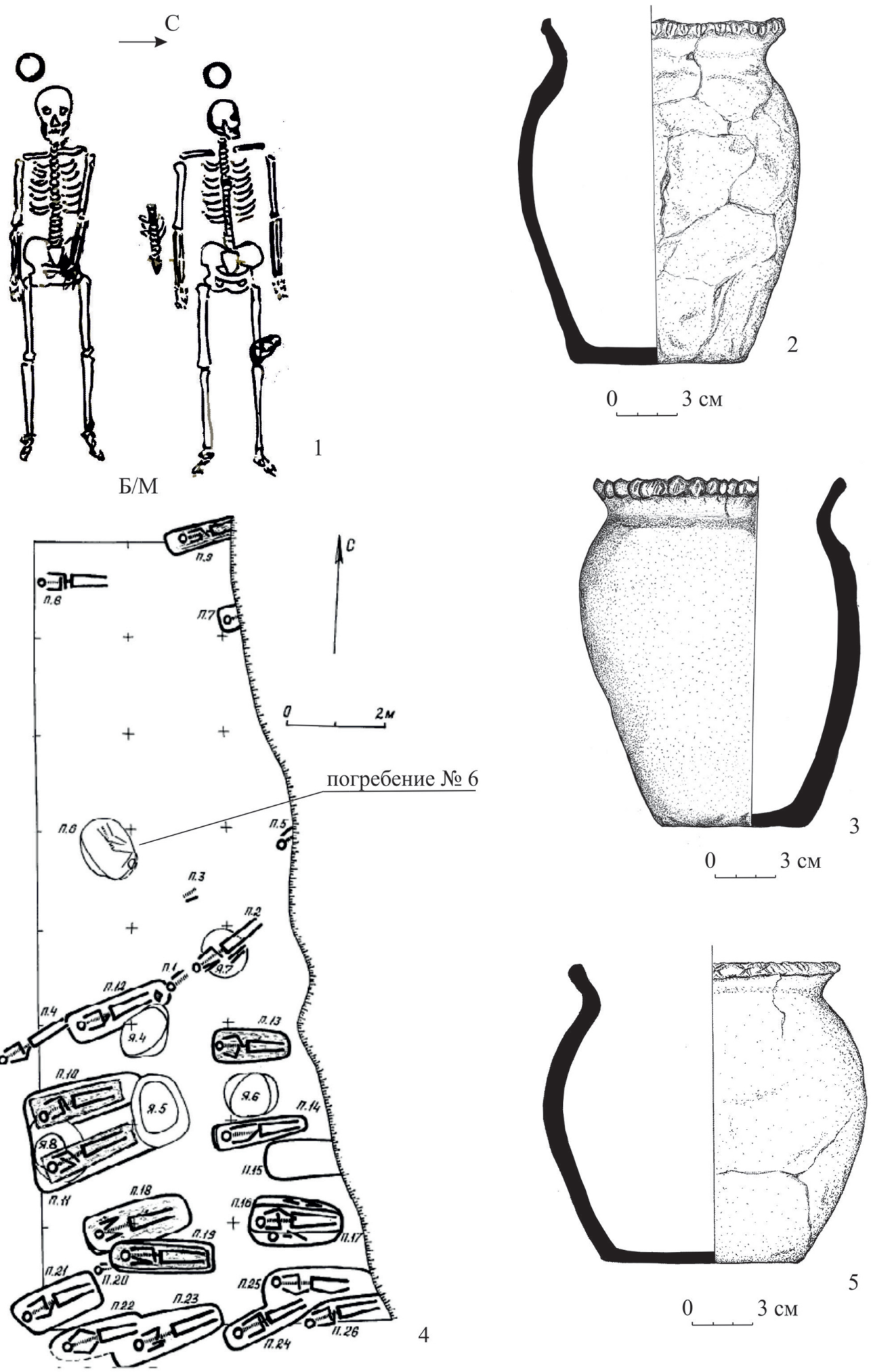

Рис. 5. Материалы грунтовых погребений из могильников Приморский и Водянского городища:

1 - план погребений могильника Приморский; 2, 3 - могильник Приморский (точное место расположения сосудов неизвестно); 4 - план русского кладбища XIV в. на территории Водянского городища; 5 - керамический сосуд из погребения № 6

Fig. 5. The materials from the ground burials of Primorsky and Vodyansky hillforts:

1 - plan of burials of Primorsky burial mound; 2, 3 - Primorsky burial mound (the exact location of vessels is unknown); 4 - plan of Russian cemetery of the $14^{\text {th }} \mathrm{c}$. in the territory of Vodyansky hillfort; 5 - the ceramic vessel from burial 6 
Я.А. Кияшко. Грунтовые захоронения на территории Волго-Донского междуречья
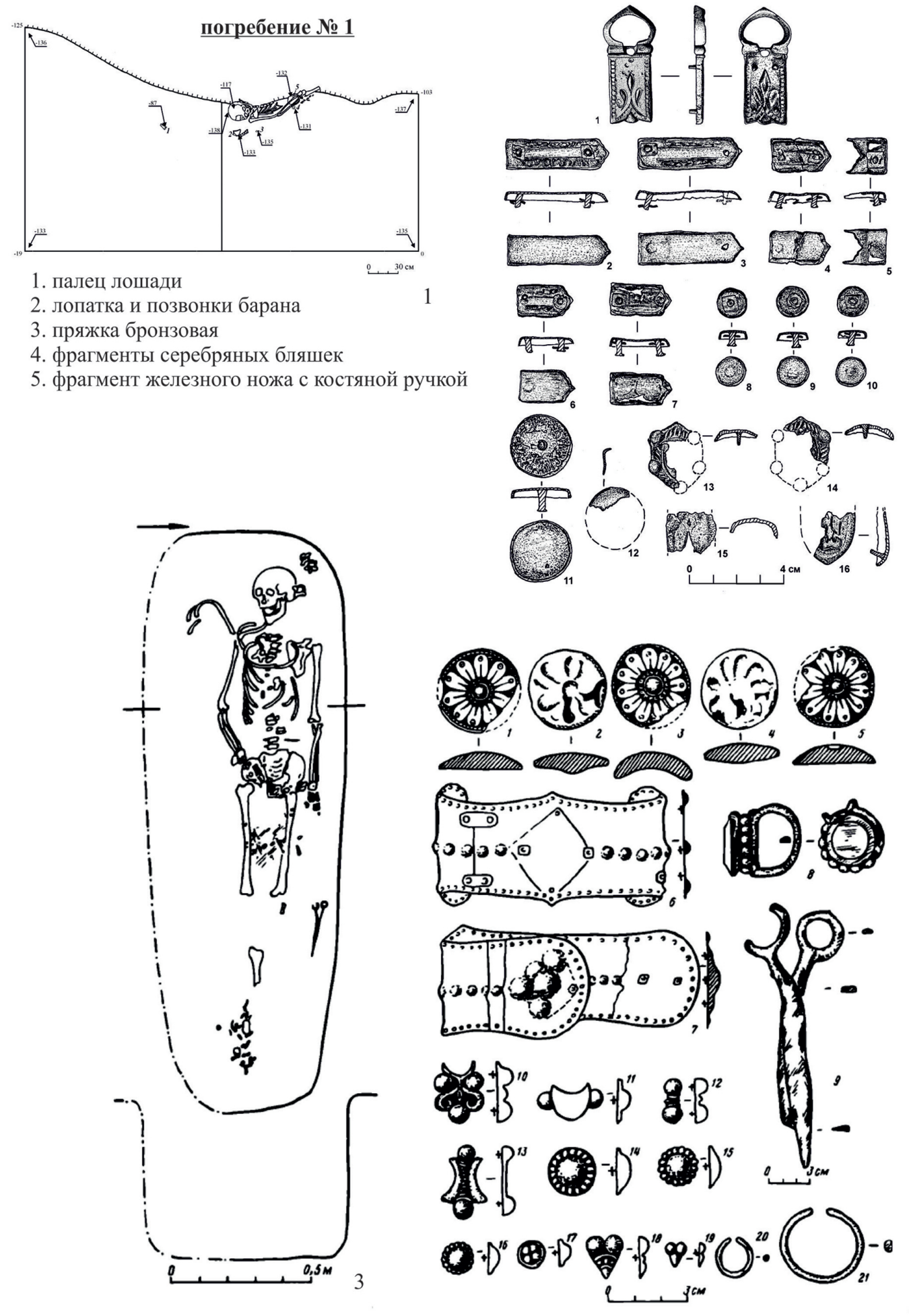

Рис. 6. Материалы грунтовых погребений из одиночных захоронений Сердитая Балка и Успенка:

1 - план погребения № 1 одиночного захоронения Сердитая Балка [Лапшин, 2008, с. 319, рис. 1];

2 - детали поясного гарнитура из погребения № 1;3 - план одиночного захоронения у с. Успенка [Шнайдштейн, 1989 , с. 270, pис. 1-2]; 4 - погребальный инвентарь из погребения № 1 у с. Успенка: 1-5 - деревянные бляхи;

6, 7 - браслеты; 8 - перстень; 9 - ножницы; 10-19 - бляхи металлические; 20 - кольцо; 21 - серьга

Fig. 6. The materials from the ground burials of Serditaya Balka and Uspenka:

1 - plan of burial 1 of Serditaya Balka ground burial; 2 - the details of waist set from burial 1 ;

3 - plan of separate burial near Uspenka; 4 - materials from burial 1 near Uspenka: $1-5$ - wooden plaques;

6, 7 - bracelets; 8 - ring; 9 - scissors; 10-19-metal plaques; 20 - ring; 21 - earring 
Ya.A. Kiyashko. Ground Burials in the Territory of the Volga-Don Interfluve

\section{ПРИМЕЧАНИЕ}

${ }^{1}$ Данная работа выполнена в рамках проекта поддержки молодых ученых ВолГУ. Автор выражает признательность А.Н. Дьяченко за оказанную помощь при подготовке статьи.

\section{СПИСОК ЛИТЕРАТУРЫ}

Артамонов М. И., 1962. История Хазар. Л. : Изд-во Гос. Эрмитажа. $523 \mathrm{c}$.

Афанасьев Г. Е., 1987. Население лесостепной зоны бассейна Среднего Дона в VIII-X вв. (аланский вариант салтово-маяцкой культуры) // Археологические открытия на новостройках. Вып. 2. М. : Наука. 200 с.

Афанасьев Г. Е., 2016. О территории Хазарского каганата и хазарского «домена» в IX веке // Дивногорский сборник. Вып. 6. Воронеж : Научная книга. С. 41-72.

Балабанова М. А., 2005. Антропология населения Нижнего Поволжья (конец V - 1-я половина IX в.) // Степи Европы в эпоху средневековья. Т. 4. Донецк : Изд-во ДонНУ. С. 55-72.

Дьяченко А. Н., Кригер В. А., 1991. Отчет о раскопках курганов и грунтового могильника в Клетском районе Волгоградской области в 1991 году // Архив ВОКМ № 109.

Иванов А. А., 1999. Раннесредневековые подкурганные кочевнические захоронения второй половины VII - первой половины IX в. Нижнего Дона и Волго-Донского междуречья : дис. ... канд. ист. наук : 07.00.06. Волгоград. 252 с.

Ильина А. И., Шишкин П. Н., 1929. Материалы к археологической карте Сталинградского, Хоперского и некоторой части Астраханского и Камышинского округов Нижневолжского края. Сталинград. $50 \mathrm{c}$.

Круглов Е. В., 1990. Новые памятники средневековья в Нижнем Поволжье // Древности Волго-Донских степей : сб. науч. ст. Вып. 1. Волгоград : Изд-во ВолГУ. С. 57-63.

Круглов Е. В., 2001. Погребальный обряд огузов Северного Прикаспия 2-й половины IX 1-й половины XI в. // Степи Европы в эпоху средневековья. Т. 2. Донецк : Изд-во ДонНУ. C. 395-446.

Круглов Е. В., 2004. Погребение хазарского времени у с. Ильевка // Хазарский альманах. Т. 2. Киев ; Харьков ; М. : Мосты культуры/Гешарим. С. $180-186$.

Круглов Е. В., 2006. Заметки на полях некоторых статей по антропологии в свете проблем археологии хазарского времени // Нижневолжский археологический вестник. Вып. 8. С. 257-301.
Круглов Е. В., 2013. О «курганах с ровиками», погребениях типа «Соколовской балки» и некоторых иных древностях хазарского времени (к постановке проблемы) // Город и степь в контактной Евро-Азиатской зоне : материалы III Междунар. науч. конф., посвящ. 75-летию со дня рождения профессора Г.А. Федорова-Давыдова (1931-2000). М. : Изд-во ГИМ, 2013. С. 74-82.

Лапшин А. С., 2008. Новый памятник эпохи Средневековья (X-XI вв.) в Волгоградском Задонье // Нижневолжский археологический вестник. Вып. 9. Волгоград : Изд-во ВолГУ. С. 318-319.

Ляпушкин И. И., 1958. Памятники салтово-маяцкой культуры в бассейне р. Дона // Материалы и исследования по археологии СССР. Т. 62. М. : Изд-во АН СССР. С. 85-150.

Мамонтов В. И., 1985. Отчет о работе Приволжского отряда ЛОИА АН СССР и Донской экспедиции НИС ВГПУ в 1985 году // Архив ВОКМ №47.

Мамонтов В. И., 1988. Отчет о работе Приволжского археологического отряда ЛОИА АН СССР и ВОКМ в 1988 году // Архив ВОКМ № 56.

Михеев В. К., 1985. Подонье в составе Хазарского Каганата. Харьков : Высшая школа. 147 с.

Мыськов Е. П., 1989. Отчет о раскопках Водянского городища, проведенных экспедициями Волгоградского пединститута в 1989 году // Архив ВОКМ № 62.

Мыськов Е. П., 2001. Русское кладбище Водянского городища // Нижневолжский археологический вестник. Вып. 4. С. 123-135.

Перерва Е. В., 2003. Палеопатологические особенности хазар из погребений Нижнего Поволжья // Нижневолжский археологический вестник. Вып. 6. С. 179-191.

Плетнева С. А., 1967. От кочевий к городам. Салтовомаяцкая культура // Материалы и исследования по археологии СССР. Т. 142. М. : Наука. 209 с.

Плетнева С. А., 1989. На славяно-хазарском пограничье (Дмитриевский археологический комплекс). М. : Наука. 288 с.

Плетнева С. А., 1999. Очерки Хазарской Археологии. М. : Мосты культуры/Гешарим. 248 с.

Путешествия в восточные страны Плано Карпини и Рубрука, 1957. Ред., вступ. ст. и примеч. Н. П. Шастиной. М. : Гос. изд-во геогр. лит. $272 \mathrm{c}$.

Федоров-Давыдов Г. А., 1966. Кочевники Восточной Европы под властью золотоордынских ханов. М. : Изд-во Моск. ун-та. 276 с.

Флеров В. С., 1993. Погребальные обряды на севере Хазарского каганата // Материалы и проблемные исследования по древней и средневековой археологии юга Восточной Европы. Вып. 2. Волгоград : Перемена. С. 34-42. 
Хоружая М. В., 2013. Захоронение в ямах с подбоем Верхне-Салтовского катакомбного могильника (по материалам раскопок 1984-2012 гг.) // Древности 2013. Харьковский историко-археологический ежегодник. Вып. 12. Харьков : HTMT. C. 211-224.

Швецов М. Л., 1983. Работы на Зливкинском могильнике// Археологические открытия-1982 . С. 341.

Шнайдштейн Е. В., 1989. Средневековое погребение на реке Ахтуба в Астраханской области // Советская археология. № 4. С. 269-272.

\section{REFERENCES}

Artamonov M.I., 1962. The History of Khazars. Leningrad, Izd-vo Gos. Ermitazha. 523 p. (in Russian).

Afanas'ev G.E., 1987. The population of the foreststeppe zone of the Middle Don basin in the VIII$\mathrm{X}$ centuries (Alanian option of Saltovo-Mayaki culture). Arkheologicheskie otkrytiia na novostroikakh, iss. 2. Moscow, Nauka Publ. 200 p. (in Russian).

Afanas'ev G.E., 2016. About the territory of the Khazar Khaganate and khazar "domain" in the IX century. Divnogorskii sbornik, iss. 6 . Voronezh, Nauchnaia kniga Publ., pp. 41-72. (in Russian).

Balabanova M.A., 2005. Anthropology of population of lower Volga reaches (end of V - first half of IX cc.). Stepi Evropy v epokhu Srednevekovia, vol. 4. Donetsk, Izd-vo DonNU, pp. 55-72. (in Russian).

Diachenko A.N., Kriger V.A., 1991. The report on the excavations of burials mounds and ground burial in Kletskiy district of the Volgograd region in 1991. Arkhiv VOKM, no. 109. (in Russian).

Ivanov A.A., 1999. Early medieval burial complexes of nomads in the second half of VII c. - the first half of IX $c$. in the territory the Lower Don and the Volga-Don interfluve. Cand. hist. sci. diss. Volgograd. 252 p. (in Russian).

Ilina A.I., Shishkin P.N., 1929. Materials of the archeological map of Stalingrad, Khopersky and some part Astrakhan and Kamyshinsky districts of the Lower Volga region. Stalingrad. 50 p. (in Russian).

Kruglov E.V., 1990. New sites of Middle Ages in the Lower Volga region. Drevnosti Volgo-Donskikh stepey: sb. nauch. st., iss 1. Volgograd, Izd-voVolGU, pp. 57-63. (in Russian).

KruglovE.V., 2001. Funeral RiteFeatures of the Oguz from the North Caspian Lowlands of the mid IX - X cc. Stepi Evropy v epokhu Srednevekovia, vol. 2. Donetsk, Izd-vo DonNU, pp. 395-446. (in Russian).
Kruglov E.V., 2004. The burial of khazar period near village Ilevka. Khazarskii almanakh, vol. 2. Kiev; Kharkov; Moscow, Mostykultury/ Gershaim Publ., pp. 180-186. (in Russian).

Kruglov E.V., 2006. Aside notes of some anthropological articles devoted to the archeological problems of Khazar period. The Lower Volga Archaeological Bulletin, iss. 8. Volgograd, Izd-vo VolGU, pp. 257-301. (in Russian).

Kruglov E.V., 2013. About "mounds with moats", the burials for example "Sokolovskoi balki" and some other artifacts of Khazar period (to the problem setting). Gorod $i$ step $v$ kontaktnoi Evro-Aziatskoi zone: materialy III Mezhdunar. nauch. konf., posviashch. 75-letiiu so dnia rozhdeniia professora G.A. FedorovaDavydova (1931-2000). Moscow, Izd-vo Gosudarstvennyi istoricheskii muzei, pp. 74-82. (in Russian).

Lapshin A.S., 2008. New sites of Middle Ages (XXI cc.) in the Volgograd Zadonie. The Lower Volga Archaeological Bulletin, iss. 9, pp. 318319. (in Russian).

Ljapushkin I.I., 1958. The sites of Saltovo-Mayaki culture in the watershed of the Don. Materialy $i$ issledovanija po arheologii SSSR, vol. 62. Moscow, Izd-vo AN SSSR, pp. 85-150. (in Russian).

Mamontov V.I., 1985. The report on work of Privolzhsky detachment of the Leningrad Academy of Sciences of the USSR and the Don Expedition of the NIS of the VSPU in 1985. Arkhiv VOKM, no. 47. (in Russian).

Mamontov V.I., 1988. The report on work of Privolzhsky archaeological detachment of the Leningrad Academy of Sciences of the USSR and in 1988. Arkhiv VOKM, no. 56. (in Russian).

Mikheev V.K., 1985. Don region in the structure of Khazar Khaganate. Kharkov, Vysshaia shkola Publ. 147 p. (in Russian).

Myskov E.P., 1989. The report on the excavations of Vodianskoe settlement lead by expeditions of the Volgograd Pedagogical Institute in 1989. Arkhiv VOKM, no. 62. (in Russian).

Myskov E.P., 2001. Russian cemetery of Vodyansky settlement. The Lower Volga Archaeological Bulletin, iss. 4, pp. 123-135. (in Russian).

Pererva E.V., 2003. Paleopathological features of the Khazars, found in burial sites of the Lower Volga Region. The Lower Volga Archaeological Bulletin, iss. 6, pp. 179-191. (in Russian).

Pletneva S.A., 1967. From nomads to the cities. Saltovo-Mayaki culture. Materialy $i$ issledovanija po arheologii SSSR, vol. 142. Moscow, Nauka Publ. 209 p. (in Russian). 
Ya.A. Kiyashko. Ground Burials in the Territory of the Volga-Don Interfluve

Pletneva S.A., 1989. On Slavic Khazar border (Dmitrievskii archaeological complex). Moscow, Nauka Publ. 288 p. (in Russian).

Pletneva S.A., 1999. Khazar archeology essays. Moscow, Mosty kultury/Gershaim Publ. 248 p. (in Russian).

Adventures of Plano Carpini and Rubruck to eastern countries, 1957. Moscow, Gos. izd-vo geogr. lit. 272 p. (in Russian).

Fedorov-Davydov G.A., 1966. Nomads of Eastern Europe under the power of khans of Golden Horde. Moscow, Izd-vo Mosk. un-ta. 276 p. (in Russian).

Flerov V.S., 1993. Burial ceremonies on the north of Khazar Khaganate. Materialy i problemnye issledovaniia po drevnei i srednevekovoi arkheologii uga Vostochnoi Evropy, iss. 2. Volgograd, Peremena Publ.,pp. 34-42. (in Russian). Khoruzhaia M.V., 2013. The burial in pits of Verkhniy Saltov catacomb burials (on the material of excavations 1984-2012 years). Drevnosti 2013. Kharkovskii istoriko-arkheologicheskii ezhegodnik, iss. 12. Kharkov, NTMT Publ., pp. 211-224. (in Russian).

Shvetsov M.L., 1983. Work on the Zlivkinskom burial complex. Arkheologicheskie otkrytiia-1982. Moscow, Nauka Publ., p. 341. (in Russian).

Shnaidshchtein E.V., 1989. Medieval burial on the Akhtuba in the Astrakhan Region. Sovetskaja arkheologiya, no. 4, pp. 269-272. (in Russian).

\section{Information about the Author}

Yakov A. Kiyashko, Postgraduate Student, Department of Archaeology, Foreign History and Tourism, Volgograd State University, Prosp. Universitetsky, 100, 400062 Volgograd, Russian Federation, kiyashko.ya@gmail.co,adsi@volsu.ru.

\section{Информация об авторе}

Яков Алексеевич Кияшко, аспирант кафедры археологии, зарубежной истории и туризма, Волгоградский государственный университет, просп. Университетский, 100, 400062 г. Волгоград, Российская Федерация, kiyashko.ya@gmail.co, adsi@volsu.ru. 